\title{
Teachers teaching misconceptions: a study of factors contributing to high school biology students' acquisition of biological evolution-related misconceptions
}

\author{
Tony B Yates ${ }^{1 *}$ and Edmund A Marek ${ }^{2}$
}

\begin{abstract}
Background: Research has revealed that high school students matriculate to college holding misconceptions related to biological evolution. These misconceptions interfere with students' abilities to grasp accurate scientific explanations and serve as fundamental barriers to understanding evolution. Because the scientific community regards evolution as a vital part of science education, it is imperative that students' misconceptions are identified and their sources revealed. The purpose of this study was to identify the types and prevalence of biological evolution-related misconceptions held by high school biology teachers and their students, and to identify those factors that contribute to student acquisition of such misconceptions, with particular emphasis given to the role of the teacher.
\end{abstract}

Methods: Thirty-five teachers who taught at least one section of Biology I during the 2010 to 2011 academic year in one of 32 Oklahoma public high schools and their respective 536 students served as this study's unit of analysis. The Biological Evolution Literacy Survey, which possesses 23 biological evolution misconception statements grouped into five categories, served as the research tool for identifying teachers' misconceptions prior to student instruction and students' misconceptions both prior to and following instruction in biological evolution concepts, calculating conception index scores, and collecting demographic data. Multiple statistical analyses were performed to identify statistically significant $(p<.05)$ relationships between variables related to student's acquisition of biological evolution-related misconceptions.

Results: Analyses revealed that students typically exit the Biology I classroom more confident in their biological evolution knowledge but holding greater numbers of misconceptions than they initially possessed upon entering the course. Significant relationships between student acquisition of misconceptions and teachers' bachelor's degree field, terminal degree, and hours dedicated to evolution instruction were also revealed. In addition, the probabilities that specific biological evolution-related misconceptions were being transmitted from teachers to their students were also identified.

Conclusions: This study reveals some problematic issues concerning the teaching of biological evolution in Oklahoma's public high school introductory biology course. No doubt, multiple factors contribute in varying degrees to the acquisition and retention of student misconceptions of biological evolution. However, based on this study's results, there is little doubt that teachers may serve as sources of biological evolution-related misconceptions or, at the very least, propagators of existing misconceptions. It is imperative that we as educators identify sources of student biological evolution-related misconceptions, identify or develop strategies to reduce or eliminate such misconceptions, and implement these strategies at the appropriate junctures in students' cognitive development.

Keywords: Biology education; Biology teachers; Evolution education; Misconception; Oklahoma; Public high school; Students

\footnotetext{
* Correspondence: tony.yates@okbu.edu

'Oklahoma Baptist University, James E. Hurley College of Science and

Mathematics, 500 West University, OBU Box 61722, Shawnee, OK 74804, USA

Full list of author information is available at the end of the article
} 


\section{Background}

A misconception is defined as 'a perception of phenomena occurring in the real world which is not consistent with the scientific explanation of the phenomena' (Modell et al. 2005, p. 20). Numerous studies reveal that high school students enter college biology courses holding misconceptions related to biological evolution (Bishop and Anderson 1990; Brumby 1984; Wescott and Cunningham 2005; Wilson 2001). These misconceptions range from minor misunderstandings to complete theory rejection (Alters and Alters 2001; Dagher and BouJaoude 2005; Evans 2001; Mazur 2004; McComas 2006; Sadler 2005) and are typically complex and strongly held, serving as fundamental barriers to students' understanding of accurate scientific explanations concerning evolution that are presented in class (Bishop and Anderson 1990; Brumby 1984; Ferrari and Chi 1998; Jiménez-Aleixandre and FernándezPérez 1987; Meir et al. 2007; Wescott and Cunningham 2005; Wilson 2001).

Misconceptions are held by novices and experts alike (Palmquist and Finley 1997). It is therefore logical to assume that teachers, too, hold a range of misconceptions (Kikas 2004). A number of studies revealed that many teachers, including those with experience, operate while holding misconceptions about various biological concepts (for example, Affanato 1986; Bishop and Anderson 1990; Brumby 1984; Chinsamy and Plagányi 2007; Clough and Wood-Robinson 1985; Demastes et al. 1995; Greene 1990; Nehm and Schonfeld 2007; Osif 1997; Settlage 1994; Yates and Marek 2013; Yip 1998). In fact, research indicates that teachers adhere to many of the same biological evolution misconceptions as their students (Bishop and Anderson 1990; Brumby 1984; Demastes et al. 1995; Nehm and Schonfeld 2007; Settlage 1994). As Nehm and Schonfeld (2007) concluded, 'one cannot assume that biology teachers with extensive backgrounds in biology have an accurate working knowledge of evolution, natural selection, or the nature of science' (p. 716).

The scientific community regards evolution as a vital part of science education (National Academy of Sciences 1998) yet evolutionary theory is one of the most commonly misunderstood areas of biology (Gregory 2009). In order to ensure that students complete their science courses with accurate understanding and working knowledge of biological evolution, it is imperative to identify sources of confusion concerning evolution (Modell et al. 2005; National Research Council 1996; Novak 2002; Wescott and Cunningham 2005). Understanding both students' and teachers' conceptions of the theory of evolution requires an investigation into the variety of factors that might influence the development of such conceptions (Hokayem and BouJaoude 2008). Much recent research concerning misconceptions in general, and misconceptions of biological evolutionary theory in particular, attempts to reveal causative agents. This research has determined that sources from which these conceptual difficulties arise are varied and complex (Modell et al. 2005). A question of particular interest in this study is: are high school biology teachers sources of students' biological evolution misconceptions?

Taught-and-learned misconceptions are misconceptions that have been taught by parents, teachers, and others or unconsciously learned from fiction (Alters and Nelson 2002). In instructor-centered teaching, the instructor determines, primarily from tradition and disciplinary content, exactly what is to be taught and how it should be taught (Alters and Nelson 2002). For teachers possessing biological evolution-related misconceptions, this suggests these teachers may convey those misconceptions to their students through inaccurate teaching (Alters and Nelson 2002; Barrass 1984; Driver et al. 1994; Fisher 2004; Haidar 1997; Jarvis et al. 2003; Lawrenz 1986; Mohapatra and Bhattacharyya 1989; Sanders 1993; Wanderssee et al. 1994; Yip 1998), critically impeding student conceptual development of accurate scientific explanations (Crawford et al. 2005; Fisher 2004; Jarvis et al. 2003; Kikas 2004). Evidence therefore indicates there is great potential for teachers' biological evolution-related misconceptions to be taught to their students (Fisher 2004; Wood-Robinson 1994).

To assess the role of biology teachers in student acquisition of biological evolution-related misconceptions, Oklahoma public high school introductory biology teachers and their students were surveyed. The teachers' initial survey was followed by a pair of surveys administered to students in a single section of each teacher's Biology I course, both prior to and following mandated instruction in biological evolution concepts. The purpose of this study was to identify biological evolution misconceptions in the teacher and student populations; determine the rate of change in students' misconceptions from preto post- biological evolution instruction; and identify variables that contribute to student acquisition of biological evolution misconceptions, including variables associated with the students, teachers, and participants' schools. Student variables addressed in the study included gender, ethnicity, grade level, and evolution knowledge self-rating, while teacher variables included gender, terminal degree, bachelor's degree major, years' teaching experience, college education evolution emphasis, hours dedicated to teaching evolution, and evolution knowledge self-rating. Participants' school variables analyzed included average daily membership (ADM), the aggregate membership of a school during a reporting period (normally a school year) divided by the number of days school is in session during this period (Institute of Education Sciences National Center for Educational Statistics 2010a); and urbancentric classification, the classification of schools based 
on locales (city, suburb, town, and rural: Institute of Education Sciences National Center for Educational Statistics 2010b). Although no claim is made that the results of this study, confined to public high schools within the state of Oklahoma, represent those of the entire country or other geographical regions, the findings are relevant and do contribute to the biological evolution misconception literature.

\section{Method}

\section{Context}

State science standards are the basis for what teachers teach and students learn and thereby establish the foundation for states' desired science education outcomes (Moore 2009). The state of Oklahoma sets academic standards and assessments aligned to those standards. The Oklahoma State Department of Education's Priority Academic Student Skills (PASS; Oklahoma State Department of Education 2009a) was developed in 1993 based on the National Science Education Standards (National Research Council 1996) and the Benchmarks for Scientific Literacy by the American Association for the Advancement of Science (1993). PASS science standards present a framework for what students should know, understand, and be able to do in the natural sciences (National Research Council 1996). High school Biology I possesses several PASS content standards that emphasize biological evolution-related concepts, about which teachers should be thoroughly knowledgeable and should accurately teach to their students in Biology I. The Oklahoma End-of-Instruction Biology I Alignment Blueprint (Oklahoma State Department of Education 2008-2009) calls for approximately $28 \%$ to $39 \%$ of the test to cover biological evolution-related concepts. PASS biological evolution-related standards were a primary reference in the development of both teacher and student survey instruments employed in this study. Both detailed PASS science standards and the Oklahoma End-ofInstruction Biology I Alignment Blueprint can be accessed via URLs identified in the References section.

\section{Participants and course}

Initially a recruitment letter was sent addressed to the Science Department Chairs of each of the 474 public high schools in the state of Oklahoma, requesting them to pass the letter on to one teacher within the high school who met the study's criteria. However, multiple teacher recruitment letters were distributed in some schools by the initial contact. A total of 76 teachers from 73 public high schools volunteered for the study, producing a $15.4 \%$ school response rate, with 35 of those teachers having met the study's requirements. Thus, participants in this study included 35 public high school biology teachers (17 men and 18 women) and their respective high school students $(N=536)$ enrolled in one Biology I course section taught by the teacher. In the event that a teacher participant taught more than one Biology I course section, the teacher selected the study's participating class. Teacher participants were employed on a full-time basis during the 2010 to 2011 academic year by a collective $32(6.8 \%)$ of the 474 public high schools (Oklahoma State Department of Education 2009b) located within the state of Oklahoma, which served as the study region. For the purposes of this study, a high school was defined as a secondary school offering any combination of grades 9 through 12 . All teacher participants possessed a current Oklahoma state teaching license obtained by meeting state licensure criteria (Oklahoma State Board of Education 2011). These criteria included a minimum of a bachelor's degree and passing scores on state certification tests. All teacher participants were certified to teach biological sciences within the state of employment and taught at least one Biology I section at the high school level during the 2010 to 2011 academic year. Each potential teacher participant who met the study's criteria and volunteered to participate was presented with an Informed Consent to Participate in a Research Study form approved by the researchers' university Office of Human Research Participant Protection.

Student participants included 536 public high school students ( 249 boys and 287 girls) enrolled during the 2010 to 2011 academic year in one of the study's public high schools. Beginning in the fall of 2010, all student participants were first-time enrollees in a Biology I course taught by one of the 35 teacher participants. Biology I, a core curriculum course that is required for high school graduation (Oklahoma State Department of Education 2009c), is typically taken by freshmen and sophomore students. Biology I investigates content, concepts, and principles of major themes in the biological sciences, including biological evolution (Oklahoma State Department of Education 2009a) and serves as the prerequisite course for subsequent biology courses students may take (Oklahoma State Department of Education 2009c). Students' participation involved regular classroom instruction activities administered by the teacher participants. Because the researcher did not interact with the students they were not required by the researchers' institute's Internal Review Board to complete an Informed Consent to Participate in a Research Study form.

\section{Instrumentation}

To identify teacher and student participants' knowledge structure and misconceptions about biological evolution, an anonymous survey was developed called the Biological Evolution Literacy Survey (BEL Survey; Yates and Marek 2011, p. 32-33). Prospective teacher participants were contacted via a recruitment letter with those 
who volunteered for the study completing the teacher version of the BEL Survey in May 2010. These teacher participants were instructed to administer the student pre-instruction version of the BEL Survey to students in one Biology I course section within the initial week of the fall 2010 semester. By administering the survey as early as possible in the course, teacher and curriculum influences on students' knowledge and opinions related to the BEL Survey statements were limited. In addition, by surveying students in only one Biology I section, peer influence was reduced. Subsequently, teachers were instructed to administer an identical post-instruction student BEL Survey following instruction in biological evolution concepts or at the completion of the course.

With permission, the BEL Survey was modeled after Cunningham and Wescott's 2009 survey which was adapted from Almquist and Cronin (1988) with additions from Wilson (2001), and Bishop and Anderson (1986, 1990). The purpose of Cunningham and Wescott's 2009 study was to identify the common misconceptions held by undergraduate students and attempt to explain the reasoning behind those misconceptions. In addition, Cunningham and Wescott were interested in assessing how students' opinions and understanding of evolutionary theory may have changed in the interim since the 1988 Almquist and Cronin study, which attempted to identify college and university students' basic knowledge concerning the processes of evolution as well as their opinions on science and religion issues.

The BEL Survey is composed of two sections, the demographics section and the survey section. Whereas the survey sections were identical for teacher and student participants, the demographics sections varied. Demographic data requested from teacher participants included gender, terminal degree, bachelor's degree major, years of teaching experience, college education emphasis on evolution, hours dedicated to teaching evolution, and self-rating of evolution knowledge (Table 1). Demographic data requested for students included gender, ethnicity, grade level, self-rating of knowledge of evolution (Table 2), and whether the student had previously enrolled in a Biology I course. Any student whose survey indicated previous enrollment in a Biology I course was omitted from the study. In addition, three questions were posed that allowed matching of pre- and post-instruction BEL Survey responses to the same student while still maintaining anonymity. These questions called for the identification of gender, birthdate, and number of both male and female siblings.

The survey section of the BEL Survey asked both teacher and student participants to respond to whether they strongly agree, somewhat agree, somewhat disagree, strongly disagree, or have no opinion ('undecided/or never heard of it') on 23 statements related to biological
Table 1 Teacher profile

\begin{tabular}{|c|c|c|c|}
\hline Demographic variable & Variables & $n$ & $\%^{a}$ \\
\hline \multirow[t]{2}{*}{ Gender } & Female & 17 & 48.6 \\
\hline & Male & 18 & 51.4 \\
\hline \multirow[t]{3}{*}{ Terminal degree } & Bachelor's & 22 & 62.9 \\
\hline & Master's & 10 & 28.6 \\
\hline & Doctorate & 3 & 8.6 \\
\hline \multirow[t]{5}{*}{ Bachelor's degree major } & Biology & 13 & 37.1 \\
\hline & Non-biology science & 8 & 22.9 \\
\hline & Science education & 7 & 20.0 \\
\hline & Non-science & 6 & 17.1 \\
\hline & No response & 1 & 2.9 \\
\hline \multirow[t]{5}{*}{ Years' teaching experience } & 0 to 5 & 7 & 20.0 \\
\hline & 6 to 10 & 4 & 11.4 \\
\hline & 11 to 15 & 6 & 17.1 \\
\hline & 16 to 20 & 7 & 20.0 \\
\hline & $>20$ & 11 & 31.4 \\
\hline \multirow[t]{5}{*}{ College education evolution emphasis } & Highly emphasized & 3 & 8.6 \\
\hline & Moderately emphasized & 14 & 40.0 \\
\hline & Slightly emphasized & 12 & 34.3 \\
\hline & Not emphasized & 5 & 14.3 \\
\hline & No response & 1 & 2.9 \\
\hline \multirow[t]{5}{*}{ Hours dedicated to teaching evolution } & 0 & 1 & 2.9 \\
\hline & 1 to 5 & 17 & 48.6 \\
\hline & 6 to 10 & 7 & 20.0 \\
\hline & 11 to 15 & 3 & 8.6 \\
\hline & $>15$ & 7 & 20.0 \\
\hline \multirow[t]{5}{*}{ Evolution knowledge self-rating } & Excellent & 7 & 20.0 \\
\hline & Good & 17 & 48.6 \\
\hline & Average & 7 & 20.0 \\
\hline & Fair & 4 & 11.4 \\
\hline & Poor & 0 & 0.0 \\
\hline
\end{tabular}

aPercentages may not total 100 due to rounding.

evolution-related misconceptions. Cronbach's alpha of 0.848 was identified for the 23-statement BEL Survey, which indicates that the internal reliability of the survey was acceptable. Additionally, if any one statement was deleted, the reliability coefficient did not decrease by more than 0.014 , thus maintaining the survey's internal reliability.

During data analysis, two methods of scoring responses were used. First, the responses 'strongly agree' and 'somewhat agree' were combined, indicating participant agreement with the statement. Likewise, the responses 'strongly disagree' and 'somewhat disagree' were combined, indicating participant disagreement with the 
Table 2 Student profile

\begin{tabular}{|c|c|c|c|}
\hline Demographic variable & Variables & $n$ & $\%^{a}$ \\
\hline \multirow[t]{2}{*}{ Gender } & Female & 287 & 53.5 \\
\hline & Male & 249 & 46.5 \\
\hline \multirow[t]{6}{*}{ Ethnicity } & $\begin{array}{l}\text { American Indian or Alaskan } \\
\text { Native }\end{array}$ & 76 & 14.2 \\
\hline & Asian or Pacific Islander & 9 & 1.7 \\
\hline & Black, non-Hispanic & 19 & 3.5 \\
\hline & Hispanic & 34 & 6.3 \\
\hline & White, non-Hispanic & 390 & 72.8 \\
\hline & No response & 8 & 1.5 \\
\hline \multirow[t]{5}{*}{ Grade level } & Freshman & 131 & 24.4 \\
\hline & Sophomore & 394 & 73.5 \\
\hline & Junior & 8 & 1.5 \\
\hline & Senior & 1 & 0.2 \\
\hline & No response & 2 & 0.4 \\
\hline Evolution knowledge self-rating & Excellent & 18 & 3.4 \\
\hline \multirow[t]{5}{*}{ (Pre-instruction) } & Good & 76 & 14.2 \\
\hline & Average & 242 & 45.1 \\
\hline & Fair & 120 & 22.4 \\
\hline & Poor & 76 & 14.2 \\
\hline & No response & 4 & 0.7 \\
\hline Evolution knowledge self-rating & Excellent & 36 & 6.7 \\
\hline \multirow[t]{5}{*}{ (Post-instruction) } & Good & 158 & 29.5 \\
\hline & Average & 254 & 47.4 \\
\hline & Fair & 63 & 11.8 \\
\hline & Poor & 23 & 4.3 \\
\hline & No response & 2 & 0.4 \\
\hline
\end{tabular}

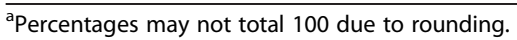

statement. Second, a biological evolution misconception scoring index for the statements was created by Likert scaling of responses with answers to statements indicative of a low acceptance of an evolution concept (high acceptance of the associated misconception) receiving low scores and responses to statements indicative of a high acceptance of an evolution concept (nonacceptance of misconception) receiving high scores. For statements in which agreement indicated a nonacceptance of the associated misconception (statements 2, 4, 8, 10, 11, 14, 15, $18,20,23$ ), index scoring was as follows: (a) strongly agree, score of 5; (b) somewhat agree, 4; (c) undecided/ never heard of it, 3; (d) somewhat disagree, 2; (e) strongly disagree, 1 ; and (f) no response, 0 . For statements in which agreement indicated a high acceptance of the associated misconception (statements 1, 3, 5, 6, 7, 9, $12,13,16,17,19,21,22$ ), index scoring was as follows: (a) strongly agree, score of 1; (b) somewhat agree, 2; (c) undecided/never heard of it, 3; (d) somewhat disagree,
4; (e) strongly disagree, 5; and (f) no response, 0 . The possible range of BEL Survey index scores was 0 to 115 with a score of 115 representing the highest level of understanding of those evolution concepts revealed by the BEL Survey coupled with a lack of associated misconceptions whereas lower indices represented lower levels of understanding combined with higher levels of misconceptions. In addition, a simple count of the number of misconceptions revealed by responses to the $23 \mathrm{BEL}$ Survey statements was conducted for both teacher and student participants.

Cunningham and Wescott's (2009) survey instrument on which the BEL Survey is modeled contained 24 statements classified into four categories: evolutionary theory, scientific facts, process of evolution, and language of science. For the present study, Cunningham and Wescott's four-category classification was modified into five categories of biological evolution-related misconceptions that are commonly employed in the literature (for example, Alters and Alters 2001; Bishop and Anderson 1990; Greene 1990; Gregory 2009; Jensen and Finley 1996; Wanderssee et al. 1994; Wescott and Cunningham 2005; Wilson 2001). These misconception categories include science, scientific methodology and terminology (SSMT); intentionality of evolution (IE); nature of evolution (NE); mechanisms of evolution (ME); and evidence supporting evolution (ESE). The SSMT and ESE misconception categories are self-described; the IE category addresses misconceptions that subscribe a type of conscious will and directive to the mechanisms of evolution; the NE category presents misconceptions concerning factors that influence biological evolution such as the environment, chance, and the roles of the individual versus the population; and the ME category illuminates misconceptions of those mechanisms that produce evolutionary change, such as mutations and natural selection. Five biological evolution-related misconception statements were identified or developed for each of the SSMT, IE, and ME categories, and four such statements were identified or developed for each of the NE and ESE categories. The resulting 23 statements were subsequently included in the BEL Survey (Table 3), whereas category identification was omitted. Two BEL Survey statements (11 and 16) were acquired directly and eight statements $(1,6,7,9,15,17,20,22)$ were adapted from Cunningham and Wescott's survey; the remaining 13 statements $(2,3,4,5,8,10,12,13,14,18,19,21,23)$ were developed through an extensive search of biological evolution misconception literature.

\section{Data analysis}

Multiple statistical analyses were performed to identify statistically significant $(p<.05)$ relationships between variables related to students' acquisition of biological 
Table 3 BEL survey statement teachers' and students' percent responses

\begin{tabular}{|c|c|c|c|c|c|c|c|c|}
\hline & \multirow[t]{2}{*}{ Category } & \multirow[t]{2}{*}{ Statement } & \multicolumn{6}{|c|}{ Percentage response $^{a}$} \\
\hline & & & 1 & 2 & 3 & 4 & 5 & 6 \\
\hline \multirow[t]{3}{*}{1} & \multirow[t]{3}{*}{ SSMT1 } & \multirow{3}{*}{$\begin{array}{l}\text { A scientific theory that explains a natural phenomenon can be } \\
\text { classified as a 'best guess' or 'hunch.' }\end{array}$} & 2.9 & 11.4 & 8.6 & 77.1 & 0.0 & 0.0 \\
\hline & & & 11.9 & 37.3 & 22.9 & 11.9 & 15.7 & 0.2 \\
\hline & & & 14.0 & 31.9 & 22.2 & 22.0 & 9.5 & 0.4 \\
\hline \multirow[t]{3}{*}{2} & \multirow[t]{3}{*}{ SSMT2 } & \multirow{3}{*}{$\begin{array}{l}\text { The scientific methods used to determine the age of fossils and the } \\
\text { earth are reliable. }\end{array}$} & 42.9 & 28.6 & 20.0 & 8.6 & 0.0 & 0.0 \\
\hline & & & 22.6 & 50.4 & 14.0 & 6.3 & 6.5 & 0.2 \\
\hline & & & 25.0 & 44.0 & 16.4 & 9.9 & 4.7 & 0.0 \\
\hline \multirow[t]{3}{*}{3} & \multirow[t]{3}{*}{ SSMT3 } & \multirow{3}{*}{$\begin{array}{l}\text { According to the second law of thermodynamics, complex life forms } \\
\text { cannot evolve from simpler life forms. }\end{array}$} & 11.4 & 11.4 & 20.0 & 28.6 & 25.7 & 2.9 \\
\hline & & & 9.5 & 11.0 & 16.8 & 17.2 & 44.8 & 0.7 \\
\hline & & & 10.8 & 17.7 & 23.5 & 21.1 & 26.3 & 0.6 \\
\hline \multirow[t]{3}{*}{4} & \multirow[t]{3}{*}{ SSMT4 } & \multirow[t]{3}{*}{ The earth is old enough for evolution to have occurred. } & 54.3 & 22.9 & 5.7 & 11.4 & 5.7 & 0.0 \\
\hline & & & 28.5 & 27.4 & 11.9 & 20.0 & 11.6 & 0.6 \\
\hline & & & 36.4 & 23.3 & 12.7 & 18.8 & 7.8 & 0.9 \\
\hline \multirow[t]{3}{*}{5} & \multirow[t]{3}{*}{ SSMT5 } & \multirow{3}{*}{$\begin{array}{l}\text { Evolution cannot be considered a reliable explanation because } \\
\text { evolution is only a theory. }\end{array}$} & 5.7 & 17.1 & 11.4 & 60.0 & 2.9 & 2.9 \\
\hline & & & 30.2 & 24.8 & 20.5 & 13.4 & 10.8 & 0.2 \\
\hline & & & 30.8 & 27.1 & 19.6 & 16.0 & 6.3 & 0.2 \\
\hline \multirow[t]{3}{*}{6} & \multirow[t]{3}{*}{ IE1 } & \multirow[t]{3}{*}{ Evolution always results in improvement. ${ }^{\mathrm{b}}$} & 5.7 & 11.4 & 25.7 & 54.3 & 2.9 & 0.0 \\
\hline & & & 6.9 & 22.8 & 28.2 & 25.4 & 14.9 & 1.9 \\
\hline & & & 7.5 & 22.4 & 30.8 & 29.3 & 8.6 & 1.5 \\
\hline \multirow[t]{3}{*}{7} & \multirow[t]{3}{*}{ IE2 } & Members of a species evolve because of an inner need to evolve. & 2.9 & 8.6 & 11.4 & 71.4 & 5.7 & 0.0 \\
\hline & & & 11.2 & 28.9 & 21.1 & 16.4 & 22.4 & 0.0 \\
\hline & & & 9.5 & 26.1 & 24.4 & 23.9 & 15.5 & 0.6 \\
\hline 8 & IE3 & Traits acquired during the lifetime of an organism - such as large muscles & 77.1 & 8.6 & 8.6 & 5.7 & 0.0 & 0.0 \\
\hline & & prc & 30.0 & 24.6 & 19.0 & 17.5 & 8.8 & 0.0 \\
\hline & & & 42.0 & 21.3 & 16.6 & 13.8 & 6.0 & 0.4 \\
\hline 9 & IE4 & If webbed feet are being selected for, all individuals in the next & 17.1 & 22.9 & 0.0 & 60.0 & 0.0 & 0.0 \\
\hline & & $\begin{array}{l}\text { generation will have more webbing on their teet than do individuals } \\
\text { in their parents' generation. }\end{array}$ & 9.1 & 1.9 & 21.8 & 11.6 & 24.6 & 0.9 \\
\hline & & & 18.3 & 35.8 & 23.1 & 11.2 & 10.6 & 0.9 \\
\hline 10 & IE5 & Evolution cannot cause an organism's traits to change within its lifetime. & 71.4 & 11.4 & 5.7 & 8.6 & 2.9 & 0.0 \\
\hline & & & 16.6 & 20.1 & 26.5 & 15.9 & 19.6 & 1.3 \\
\hline & & & 20.1 & 29.9 & 20.7 & 18.5 & 9.9 & 0.9 \\
\hline 11 & NE1 & New traits within a population appear at random. ${ }^{c}$ & 48.6 & 25.7 & 14.3 & 8.6 & 2.9 & 0.0 \\
\hline & & & 10.3 & 30.6 & 26.9 & 13.8 & 17.9 & 0.6 \\
\hline & & & 9.9 & 28.5 & 31.0 & 22.2 & 8.0 & 0.4 \\
\hline 12 & NE2 & Individual organisms adapt to their environments. & 20.0 & 22.9 & 11.4 & 45.7 & 0.0 & 0.0 \\
\hline & & & 49.4 & 32.1 & 8.2 & 4.1 & 5.2 & 0.9 \\
\hline & & & 44.2 & 32.8 & 11.4 & 7.8 & 3.0 & 0.7 \\
\hline 13 & NE3 & Evolution is a totally random process. & 22.9 & 20.0 & 20.0 & 34.3 & 2.9 & 0.0 \\
\hline & & & 10.1 & 16.0 & 24.4 & 25.4 & 23.7 & 0.4 \\
\hline & & & 11.6 & 19.0 & 26.3 & 30.0 & 12.5 & 0.6 \\
\hline 14 & NE4 & The environment determines which traits are best suited for survival. & 51.4 & 37.1 & 11.4 & 0.0 & 0.0 & 0.0 \\
\hline & & & 24.3 & 33.6 & 17.2 & 11.9 & 12.3 & 0.7 \\
\hline & & & 31.3 & 34.0 & 20.7 & 8.8 & 5.0 & 0.2 \\
\hline
\end{tabular}


Table 3 BEL survey statement teachers' and students' percent responses (Continued)

\begin{tabular}{|c|c|c|c|c|c|c|c|}
\hline \multirow[t]{3}{*}{15} & \multirow[t]{3}{*}{ ME1 } & \multirow{3}{*}{$\begin{array}{l}\text { Variation among individuals within a species is important for } \\
\text { evolution to occur. }{ }^{b}\end{array}$} & 74.3 & 17.1 & 8.6 & 0.0 & 0.0 \\
\hline & & & 11.2 & 28.0 & 18.8 & 9.3 & 32.6 \\
\hline & & & 21.5 & 34.3 & 19.0 & 12.1 & 12.5 \\
\hline \multirow[t]{3}{*}{16} & \multirow[t]{3}{*}{ ME2 } & \multirow[t]{3}{*}{ 'Survival of the fittest' means basically that 'only the strong survive.'c } & 8.6 & 31.4 & 17.1 & 42.9 & 0.0 \\
\hline & & & 35.8 & 27.2 & 17.2 & 12.5 & 7.1 \\
\hline & & & 44.8 & 24.4 & 13.6 & 12.7 & 4.5 \\
\hline \multirow[t]{3}{*}{17} & \multirow[t]{3}{*}{ ME3 } & \multirow[t]{3}{*}{ The size of the population has no effect on the evolution of a species. ${ }^{b}$} & 2.9 & 0.0 & 31.4 & 65.7 & 0.0 \\
\hline & & & 12.5 & 17.4 & 33.2 & 21.8 & 14.9 \\
\hline & & & 12.7 & 21.6 & 27.6 & 29.7 & 7.8 \\
\hline \multirow[t]{3}{*}{18} & \multirow[t]{3}{*}{ ME4 } & \multirow{3}{*}{$\begin{array}{l}\text { Complex structures such as the eye could have been formed } \\
\text { by evolution. }\end{array}$} & 34.3 & 17.1 & 11.4 & 34.3 & 2.9 \\
\hline & & & 10.8 & 26.1 & 17.4 & 25.9 & 19.2 \\
\hline & & & 15.5 & 22.4 & 21.1 & 29.9 & 10.6 \\
\hline \multirow[t]{3}{*}{19} & \multirow[t]{3}{*}{ ME5 } & \multirow[t]{3}{*}{ Only beneficial traits are passed on from parent to offspring. } & 0.0 & 0.0 & 17.1 & 82.9 & 0.0 \\
\hline & & & 8.8 & 21.5 & 26.5 & 34.0 & 8.2 \\
\hline & & & 7.8 & 23.9 & 21.8 & 40.1 & 6.0 \\
\hline \multirow[t]{3}{*}{20} & \multirow[t]{3}{*}{ ESE1 } & \multirow{3}{*}{$\begin{array}{l}\text { There exists a large amount of evidence supporting the theory } \\
\text { of evolution. }\end{array}$} & 51.4 & 11.4 & 11.4 & 22.9 & 2.9 \\
\hline & & & 14.0 & 22.2 & 19.2 & 23.9 & 20.3 \\
\hline & & & 14.6 & 28.4 & 21.8 & 26.5 & 8.6 \\
\hline \multirow[t]{3}{*}{21} & \multirow[t]{3}{*}{ ESE2 } & \multirow{3}{*}{$\begin{array}{l}\text { According to the theory of evolution, humans evolved from } \\
\text { monkeys, gorillas, or apes. }\end{array}$} & 17.1 & 14.3 & 1.4 & 54.3 & 2.9 \\
\hline & & & 25.9 & 25.0 & 10.6 & 30.2 & 8.2 \\
\hline & & & 23.9 & 23.5 & 12.1 & 34.1 & 6.3 \\
\hline \multirow[t]{3}{*}{22} & \multirow[t]{3}{*}{ ESE3 } & \multirow{3}{*}{$\begin{array}{l}\text { Scientific evidence indicates that dinosaurs and humans lived at the } \\
\text { same time in the past. }\end{array}$} & 8.6 & 14.3 & 5.7 & 62.9 & 8.6 \\
\hline & & & 13.6 & 20.7 & 17.7 & 28.2 & 19.0 \\
\hline & & & 12.7 & 20.5 & 21.6 & 32.5 & 12.3 \\
\hline \multirow[t]{3}{*}{23} & \multirow[t]{3}{*}{ ESE4 } & \multirow{3}{*}{$\begin{array}{l}\text { The majority of scientists favor evolution over other explanations } \\
\text { for life. }\end{array}$} & 42.9 & 34.3 & 17.1 & 5.7 & 0.0 \\
\hline & & & 16.4 & 28.4 & 21.8 & 10.6 & 22.2 \\
\hline & & & 20.0 & 34.7 & 20.5 & 12.1 & 12.3 \\
\hline
\end{tabular}

Percent response is identified as follows: first row, teacher participants $(N=35)$; second row, pre-instruction student participants $(N=536)$; third row, post-instruction student participants $(\mathrm{N}=536)$. Bold areas indicate percentage of participants accepting the statement-related misconception. ${ }^{\mathrm{a}}$ Percentages may not total 100 due to rounding; ${ }^{b}$ statement adapted from Cunningham and Wescott (2009); ${ }^{c}$ statement taken directly from Cunningham and Wescott (2009). $1=$ strongly agree; $2=$ somewhat agree; 3 = somewhat disagree; $4=$ strongly disagree; $5=$ undecided/never heard of it; $6=$ no response. ESE, evidence supporting evolution; $I E$, intentionality of evolution; $M E$; mechanisms of evolution; NE, nature of evolution; SSMT, science, scientific methodology, and terminology.

evolution-related misconceptions. Dependent-samples $t$-tests were conducted to compare students' mean data to specific variables. These variables included pre- and post-instruction BEL Survey mean index scores, number of misconceptions, student self-knowledge rating, and student BEL Survey Likert scale responses.

Independent-samples $t$-tests were conducted to evaluate the null hypotheses stating there were no significant differences $(p<.05)$ between the mean difference in the number of students' pre- and post-instruction misconceptions based on students' or teachers' gender. Independent-samples $t$-tests were utilized to identify significant differences $(p<.05)$ between the mean change in the number of students' pre-and post-instruction biological evolution misconceptions when student data from teachers in a High Index Score Group (HISG) and those in a Low Index Score Group (LISG) were compared. Finally, independent-samples $t$-tests were employed in identifying significant differences $(p<.05)$ in the mean change in students' pre- to post-instruction misconception numbers related to whether the students' teachers possessed or did not possess the specified misconceptions.

One-way analysis of variance (ANOVA) were performed to identify significant differences $(p<.05)$ between the mean difference in number of students' pre- and postinstruction misconceptions and student, teacher, and school variables. Student variables included grade, ethnicity, and both pre- and post-instruction biological evolution knowledge self-ratings. Teacher variables included terminal degree, bachelor's degree major, years of teaching experience, college emphasis placed on evolution, evolution knowledge rating, and number of hours dedicated to 
teaching evolution in the Biology I course. Public high school variables of urban-centric classification and ADM were analyzed to determine if public high school location and/or student population size played significant roles in the difference between the mean number of students' preand post- instruction biological evolution misconceptions. Dunnett's T3 test was utilized as a follow-up test to evaluate pairwise differences among means for statistically significant ANOVA results.

To assess the degree to which the numbers of teachers' misconceptions were linearly related to students' postinstruction BEL Survey index scores, Pearson productmoment correlation coefficient $(r)$ was utilized. Finally, a chi-square goodness-of-fit statistical analysis was employed to identify any significant differences $(p<.05)$ among variables related to the participants' public high schools when compared to the total number of public high schools within the study region. Those variables included urbancentric location and ADM.

\section{Results}

\section{Participant demographics}

Table 1 presents the teacher participant profile. Gender was evenly distributed with 17 men and 18 women. While all teacher participants possessed bachelor's degrees, $37.1 \%(n=13)$ held graduate degrees as well. Biology bachelor's degrees were held by $37.1 \%$ of the participants $(n=13)$ whereas science education degrees, non-biology science degrees, and non-science degrees were fairly evenly distributed among the remaining participants, ranging from $17.1 \%$ to $22.9 \%$. Prior to this study, $20.0 \%(n=7)$ of the teacher participants had five or fewer years of teaching experience; $31.4 \%(n=11)$ ten or fewer years teaching experience; and $31.4 \%(n=11)$ had accumulated over 20 years of experience in the classroom. When asked to identify the emphasis given to evolution in their college education, $48.6 \%(n=17)$ of participants indicated that evolution was either highly or moderately emphasized and an identical 48.6\% $(n=17)$ noted the emphasis given to evolution was either slight or non-existent. In rating their knowledge of evolution, $68.6 \%(n=24)$ contended their knowledge of evolution was either excellent or good whereas $31.4 \%(n=11)$ maintained an average or fair knowledge of evolution. None of the teacher participants considered their knowledge of evolution to be poor.

Table 2 presents the student participant profile. Female students comprised $53.5 \%(n=287)$ of the participants and male students the remaining 46.5\% $(n=249)$. The majority of student participants were sophomores (73.5\%, $n=394$ ) with freshmen accounting for $24.4 \%$ ( $n=131)$. White non-Hispanic student participants were the majority ethnic group $(72.8 \%, n=390)$ whereas students of Asian or Pacific Islander descent were in the minority, representing only $1.7 \%(n=9)$ of student participants.

\section{Public high school variables}

Analyses were conducted to identify any significant differences $(p<.05)$ among variables related to the 32 public high schools representing the study's teacher and student participants when compared to the 474 public high schools located within the study region. A comparison between the two sets of schools focused on two variables: distribution of student ADM and urban-centric classification. A chisquare goodness-of-fit statistical analysis revealed no significant difference between the two high school groups for ADM distribution $\left(\chi^{2}(4, N=32)=8.32, p>.05\right)$ but did reveal a significant difference in urban-centric classification $\left(\chi^{2}(3, N=32)=14.14, p<.05\right.$; Table 4$)$. These results indicate that the public high schools from which teacher and student participants originated were representative of the collective public high schools within the study area in ADM distribution but not in urban-centric classification. A 16.75 confidence interval at a $95 \%$ confidence level was determined for the sample of high schools containing study participants $(n=32)$ compared to the total number of public high schools $(N=474)$ located within the study area.

\section{Comparison of students' pre- and post-instruction BEL survey results}

Dependent-samples $t$-tests were conducted to compare students' mean data with specific variables. The results

Table 4 Public high school profile

\begin{tabular}{llll}
\hline $\begin{array}{l}\text { Demographic } \\
\text { variable }\end{array}$ & Variable range & \multicolumn{2}{l}{ Percentage of high schools ${ }^{\mathbf{a}}$} \\
\cline { 3 - 4 } & & $\begin{array}{l}\text { Participant } \\
(\boldsymbol{n}=\mathbf{3 2})\end{array}$ & $\begin{array}{l}\text { Study area } \\
(\boldsymbol{N}=\mathbf{4 7 4})\end{array}$ \\
\hline Average daily $_{\text {membership }}$ & 4451.85 to 485.57 & 25.0 & 20.0 \\
& 482.10 to 242.95 & 25.0 & 20.0 \\
& 242.30 to 134.10 & 21.9 & 20.0 \\
& 132.10 to 78.11 & 9.4 & 20.0 \\
& 77.73 to 14.85 & 18.8 & 20.0 \\
Urban-centric $^{c, 0}$ & City & 3.1 & 7.2 \\
classification $^{\text {d }}$ & Suburban & 6.3 & 5.7 \\
& Town & 31.2 & 17.7 \\
& Rural & 59.4 & 69.4
\end{tabular}

${ }^{a}$ Participant high schools contain study participants whereas study area high schools are the total number of high schools within the study area. Percentages may not equal $100 \%$ due to rounding ${ }^{b}$ Average daily membership is the aggregate membership of a school during a reporting period (normally a school year) divided by the number of days school is in session during this period (Institute of Education Sciences National Center for Educational Statistics 2010a). 'Urban-centric classification (Institute of Education Sciences National Center for Educational Statistics 2010b).

${ }^{\mathrm{d} D i f f e r e n c e}$ is statistically significant at $p<.05$. 
of these analyses are found in Table 5. Analysis revealed students' post-instruction BEL Survey mean index scores $(M=71.72, S D=8.80)$ were significantly higher $(p<.01)$ than were their pre-instruction BEL Survey mean index scores $(M=70.11, S D=6.97)$. In addition, a significant difference $(p<0.01)$ between the mean number of students' pre-instruction BEL Survey 'undecided/never heard of it' responses and the mean number of post-instruction BEL Survey 'undecided/never heard of it' responses was coupled with significant differences $(p<.01)$ in the mean number of pre- and post-instruction 'strongly agree' responses and 'strongly disagree' responses. There were no significant differences produced between the mean number of 'somewhat agree' or 'somewhat disagree' responses, pre- versus post-instruction.

The number of misconceptions held by students on the pre-instruction survey totaled 4,812 , producing a mean misconception rate per student of $8.98(S D=2.75)$, whereas the number of misconceptions held by students following instruction increased to a total of 5,072 with an accompanying student mean increase of 0.48 to 9.46 $(S D=2.59)$. Analyses revealed the mean number of student pre-instruction misconceptions was significantly lower $(p<.01)$ than the mean number of student post-instruction misconceptions. Of the 536 student

Table 5 Summary of analyses of dependent-samples $t$-test results for students' mean data related to specific variables

\begin{tabular}{|c|c|c|c|c|c|c|}
\hline Variable & Test & $d f$ & Mean & $S D$ & $t$ & $p$ (two-tailed) \\
\hline \multirow{2}{*}{$\begin{array}{l}\text { BEL Survey mean index } \\
\text { score }\end{array}$} & Pre & 535 & 70.11 & 6.97 & 4.19 & $<.01^{a}$ \\
\hline & Post & & 71.72 & 8.80 & & \\
\hline \multirow{2}{*}{$\begin{array}{l}\text { Number of } \\
\text { misconceptions }\end{array}$} & Pre & 535 & 8.98 & 2.75 & 3.33 & $<.01^{a}$ \\
\hline & Post & & 9.46 & 2.59 & & \\
\hline \multirow{2}{*}{$\begin{array}{l}\text { Student self-knowledge } \\
\text { rating }\end{array}$} & Pre & 530 & 3.30 & 0.99 & 10.97 & $<.01^{\mathrm{a}}$ \\
\hline & Post & & 2.77 & 0.90 & & \\
\hline \multicolumn{7}{|l|}{$\begin{array}{l}\text { Student BEL Survey } \\
\text { responses: }\end{array}$} \\
\hline \multirow[t]{2}{*}{ Strongly agree } & Pre & 535 & 4.20 & 2.87 & 4.82 & $<.01^{\mathrm{a}}$ \\
\hline & Post & & 4.88 & 3.04 & & \\
\hline \multirow[t]{2}{*}{ Somewhat agree } & Pre & 535 & 6.07 & 2.84 & 1.39 & .17 \\
\hline & Post & & 6.28 & 3.09 & & \\
\hline \multirow[t]{2}{*}{ Strongly disagree } & Pre & 535 & 4.05 & 2.66 & 5.51 & $<.01^{\mathrm{a}}$ \\
\hline & Post & & 4.80 & 2.98 & & \\
\hline \multirow[t]{2}{*}{ Somewhat disagree } & Pre & 535 & 4.62 & 2.80 & 1.07 & .28 \\
\hline & Post & & 4.77 & 2.76 & & \\
\hline \multirow{2}{*}{$\begin{array}{l}\text { Undecided/never } \\
\text { heard of it }\end{array}$} & Pre & 535 & 3.92 & 3.84 & 10.49 & $<.01^{\mathrm{a}}$ \\
\hline & Post & & 2.15 & 2.53 & & \\
\hline
\end{tabular}

${ }^{a}$ Difference between pre- and post-test means was statistically significant at $p \leq .01$. BEL, Biological Evolution Literacy; $d f$, degrees of freedom; post, student post-instruction; pre, student pre-instruction; SD, standard deviation. participants, 216 decreased in the number of misconceptions from pre- to post-instruction, 259 increased in the number of misconceptions, and for the remaining 61 students the number of misconceptions remained unchanged.

\section{Student variables}

An independent-samples $t$-test was conducted to evaluate the null hypothesis stating there was no significant difference between the mean difference in the number of pre- and post-instruction misconceptions for male versus female students (Table 6). Although the $t$-test result was not significant, female students in the study did possess a higher mean difference between pre- and post-instruction number of misconceptions $(M=+0.60$, $S D=3.39)$ as compared to male $(M=+0.35, S D=3.36)$.

One-way ANOVA were performed to evaluate the relationship between the mean difference in number of students' pre- and post-instruction misconceptions and various student variables. The ANOVA results can be found in Table 7. ANOVA conducted to evaluate the relationship between the mean difference in number of pre- and post-instruction misconceptions when compared to student ethnicities, grade level, and pre- and post-instruction ratings of biological evolution knowledge proved to be non-significant. In addition, two variables associated with students' public high schools were evaluated with ANOVA to determine the variables' relationships to the mean difference in number of students' pre- and post-instruction misconceptions. For both the independent variables of ADM and urban-centric location, the ANOVA results were non-significant (Table 7).

A dependent-samples $t$-test was subsequently conducted to evaluate whether there existed a significant difference between students' mean pre-instruction selfrating of biological evolution knowledge and their mean post-instruction self-rating (Table 5). For analysis, the self-rating classes were numerically scaled as follows: poor, 5; fair, 4; average, 3; good, 2; and excellent, 1.

Table 6 Summary of independent-samples $t$-test analyses for students' mean difference in pre- to post-instruction mean number of misconceptions related to gender

\begin{tabular}{|c|c|c|c|c|c|}
\hline \multirow[b]{2}{*}{ Variable } & \multicolumn{2}{|c|}{$\begin{array}{l}\text { Mean difference in student } \\
\text { pre- to post-instruction } \\
\text { misconception number (SD) }\end{array}$} & \multirow[b]{2}{*}{$\mathbf{t}$} & \multirow[b]{2}{*}{ df } & \multirow[b]{2}{*}{$p$} \\
\hline & Female & Male & & & \\
\hline \multirow[t]{2}{*}{ Students } & +0.60 & +0.35 & 0.84 & 533 & .40 \\
\hline & (3.39) & (3.36) & & & \\
\hline \multirow[t]{2}{*}{ Teachers } & +0.22 & +0.73 & -1.75 & 534 & .08 \\
\hline & (3.33) & $(3.41)$ & & & \\
\hline
\end{tabular}

$\mathrm{df}$, degrees of freedom; SD, standard deviation. 


\begin{tabular}{|c|c|c|c|c|}
\hline Source & $d f$ & $F$ & $\eta$ & $p$ \\
\hline \multicolumn{5}{|l|}{ High school variables: } \\
\hline Urban-centric classification & 3 & 0.72 & .07 & .54 \\
\hline Average daily membership & 4 & 0.36 & .05 & .84 \\
\hline \multicolumn{5}{|l|}{ Student variables: } \\
\hline Grade & 3 & 1.17 & .08 & .32 \\
\hline Ethnicity & 4 & 0.41 & .06 & .80 \\
\hline Pre knowledge self-rating & 4 & 1.14 & .09 & .34 \\
\hline Post knowledge self-rating & 4 & 1.09 & .09 & .36 \\
\hline \multicolumn{5}{|l|}{ Teacher variables: } \\
\hline Terminal degree & 2 & 6.38 & .15 & $<.01^{\mathrm{a}}$ \\
\hline Bachelor's degree major & 3 & 3.58 & .15 & $.01^{\mathrm{a}}$ \\
\hline Years of teaching experience & 4 & 7.07 & .07 & .59 \\
\hline College evolution emphasis & 3 & 1.85 & .10 & .14 \\
\hline Knowledge rating & 3 & 0.73 & .06 & .53 \\
\hline Hours teaching evolution & 4 & 3.95 & .17 & $<.01^{\mathrm{a}}$ \\
\hline
\end{tabular}

Analysis was conducted between specified groups of each source. ${ }^{\mathrm{a}}$ Difference between groups was statistically significant at $p \leq .01$. df, degrees of freedom.

Results indicate that students' mean post-instruction self-rating score of biological evolution knowledge $(M=2.77, S D=0.90)$ was significantly lower $(p<.01)$ than their mean pre-instruction self-rating score $(M=3.30$, $S D=0.99)$, indicating that students presumed themselves to be more knowledgeable concerning biological evolutionary concepts following instruction as opposed to prior to instruction.

\section{Teacher variables}

An independent-samples $t$-test was conducted to evaluate changes in the mean difference in the number of students' pre- and post-instruction misconceptions based on the gender of the students' teachers (Table 6). Although students of male teachers $(n=278)$ did have a $232.8 \%$ increase in the mean number of pre- and postinstruction misconceptions $(M=0.73, S D=3.41)$ over that of students of female teachers $(n=258, M=0.22$, $S D=3.33$ ), analysis indicated that teachers' gender did not produce a statistically significant difference in the mean difference in number of student's pre- and postinstruction misconceptions $(p=.08)$.

ANOVA was employed to evaluate the relationship between the mean difference in the number of students' pre- and post-instruction misconceptions and teacher variables. The results of these analyses are located in Table 7. Teachers' terminal degree included three levels: bachelor's, master's, and doctorate. The ANOVA relating the mean difference in the number of students' pre- and post-instruction misconceptions and teachers' terminal degrees was significant $(p<.01)$. Because the overall $F$ test was significant, follow-up tests were conducted to evaluate pairwise differences among the means. Because there may have been a lack of power associated with the test due to the small sample size of students of teachers possessing doctorate degrees $(n=43)$, the results of the Dunnett's T3 test, a multiple comparison procedure that does not require the population variance to be equal, was implemented. A significant difference $(p<.01)$ in the means between those students whose teachers possessed a bachelor's degree $(M=0.27$, $S D=3.36)$ and those students whose teachers possessed doctorate degrees $(M=2.21, S D=3.39)$ was revealed, as was a significant difference $(p=.01)$ between the means of students whose teachers possessed master's degrees $(M=0.45, S D=3.28)$ and those students whose teachers possessed doctorates. An ANOVA was also conducted to evaluate the relationship between the mean difference in the numbers of students' pre- and post-instruction misconceptions and teachers' bachelor's degree major. The independent variable, the teachers' bachelor's degree major, included four classes: non-science degree, science education degree, non-biology science degree, and biology degree. Because the overall $F$ test was significant $(p=.01)$, follow-up tests were conducted to evaluate pairwise differences among the means. Because the variances among the four groups ranged from 9.21 to 13.79 , it was not assumed that the variances were homogeneous and a post hoc comparison was conducted with the use of Dunnett's T3 test. A significant difference $(p<.05)$ was discovered in the mean difference in the numbers of students' pre- and post-instruction misconceptions between students' whose teachers held non-science bachelor degrees $(M=1.50, S D=3.71)$ and those students whose teachers held science education bachelor degrees $(M=.08, S D=3.04)$. A significant difference $(p<.05)$ was also revealed in the means between students whose teachers held non-science bachelor degrees and those students whose teachers held non-biology science degrees $(M=.57, S D=3.34)$.

ANOVA were conducted to evaluate the relationship between the mean difference in the number of students' pre- and post-instruction misconceptions and their teachers' years of teaching experience, ratings of emphasis placed on biological evolution in their college course, and knowledge rating of evolution. None of the ANOVA results for these three variables proved to be significant (Table 7). Finally, ANOVA was conducted to evaluate the relationship between the mean difference in the number of students' pre- and post-instruction misconceptions and the number of hours their teachers dedicated to teaching evolution in the Biology I course. The 
independent variable, hours spent teaching evolution, included five categories: 0,1 to 5,6 to 10,11 to 15 , and greater than 15 hours. The ANOVA proved to be significant, $(p<.01$; see Table 7$)$. Because the overall $F$ test was significant, follow-up tests were conducted to evaluate pairwise differences among the means. Because the variances among the five groups ranged from 8.87 to 14.03 , it was not assumed that the variances were homogeneous and because there may have been a lack of power associated with the test due to the small sample size of students of teachers dedicating 0 hours $(n=17)$ and those dedicating 11 to 15 hours $(n=45)$, the Dunnett's T3 test was utilized. A significant difference $(p<.05)$ in the means between those students whose teachers dedicated 0 hours to the teaching of biological evolution $(M=-1.0, S D=2.98)$ and those students whose teachers dedicated 11 to 15 hours to the topic $(M=2.0, S D=3.49)$ was revealed as was a significant difference between the means of students whose teachers dedicated 6 to 10 hours $(M=.01, S D=3.28)$ and those who dedicated 11 to 15 hours to the teaching of evolution.

\section{BEL survey statement analysis}

The 35 teachers' BEL Survey index scores were ranked from highest to lowest and divided into two groups. The group containing the 18 highest ranking teacher $\mathrm{BEL}$ Survey index scores $(M=103.11, S D=5.72)$ was designated the HISG whereas the group containing the 17 lowest ranking BEL Survey index scores $(M=79.64$, $S D=9.74$ ) was designated the LISG. Independent $t$-test analysis revealed significant differences between both the mean change in students' pre- and post-instruction BEL Survey index scores $(p<.01)$ and the mean change in the number of students' pre- and post-instruction biological evolution misconceptions $(p<.05)$ when student data from the HISG and LISG teacher groups were compared (Table 8). Those students of teachers in the HISG

\begin{tabular}{|c|c|c|c|c|c|}
\hline \multirow[b]{2}{*}{ Student variable } & \multicolumn{2}{|c|}{$\begin{array}{l}\text { Mean difference in student } \\
\text { variable pre- to post- } \\
\text { instruction (SD) }\end{array}$} & \multirow[b]{2}{*}{$t$} & \multirow[b]{2}{*}{$d f$} & \multirow[b]{2}{*}{$p$} \\
\hline & $\begin{array}{l}\text { Teacher HISG } \\
(n=290)\end{array}$ & $\begin{array}{l}\text { Teacher LISG } \\
(n=246)\end{array}$ & & & \\
\hline \multirow[t]{2}{*}{ BEL-mean index score } & +2.58 & +0.47 & 2.75 & 534 & $<.01^{a}$ \\
\hline & $(9.25)$ & $(8.40)$ & & & \\
\hline \multirow[t]{2}{*}{ Misconception number } & +0.20 & +0.82 & 2.11 & 534 & $.04^{b}$ \\
\hline & $(3.48)$ & $(3.23)$ & & & \\
\hline
\end{tabular}

${ }^{\mathrm{a}}$ Difference between groups is statistically significant at $p<.01$. ${ }^{\mathrm{b}}$ Difference between groups is statistically significant at $p<.05$. BEL, Biological Evolution Literacy; HISG, high index score group; LISG, low index score group, SD, standard deviation. $(n=290)$ had a mean increase of 2.58 index points $(S D=9.25)$ from pre- to post-instruction whereas those students of teachers in the LISG $(n=246)$ had a mean increase of only 0.47 index points $(S D=8.40)$. Similarly, students of HISG teachers had a mean increase of 0.20 misconceptions $(S D=3.48)$ from pre- to post-instruction whereas students of the LISG teachers had a mean increase of 0.82 misconceptions $(S D=3.23)$.

To determine the relationship between teachers' biological evolution misconceptions and their students' acquisition of the same misconceptions, from pre- to postinstruction, each teacher's responses to the BEL Survey's 23 statements were analyzed to determine which specific misconceptions they did and did not possess. Students' collective mean change in the number of each specific statement misconception, from pre-instruction to postinstruction, was calculated for students whose teachers held the specific statement misconception and for students whose teachers lacked the statement misconception, that is, possessed the accurate concept. Only students whose teachers possessed either the statement's misconception or accurate concept were entered into analysis. Students of teachers who selected 'undecided/ never heard of it' as a response or who did not have an opinion concerning the statement were not entered into the analysis. Results of the independent $t$-test analysis are revealed shown in Table 9.

For both statements 1 ('A scientific theory that explains a natural phenomenon can be defined as a "best guess" or "hunch"') and 20 ('There exists a large amount of evidence supporting the theory of evolution'), significant differences $(p<.05)$ were discovered between the mean change in the number of misconceptions held by students whose teachers possessed the statement misconception compared to students whose teachers possessed the accurate statement concept. Students whose teachers possessed the misconception associated with statement 1 had a statistically significant $(p<.05)-0.19$ decrease in the mean number of misconceptions from pre- to post-instruction as compared to a -0.01 decrease in the mean number of misconceptions for students whose teachers possessed the accurate biological evolution concept for the statement. However, students whose teachers possessed the statement 20 misconception had a 0.22 increase in the mean number of misconceptions from pre- to post-instruction as compared to a -0.01 mean decrease for students whose teachers possessed the accurate biological evolution concept, producing a significant difference between the two of $p<.01$.

Analysis revealed there to be ten BEL Survey statements $(2,3,5,14,16,17,18,20,22$, and 23) in which the mean change in the number of misconceptions held by students whose teachers accepted the statement misconception was greater than that for students of teachers 
Table 9 Mean change in students' pre- to post-instruction misconception numbers related to teachers' with and without statement misconception

\begin{tabular}{|c|c|c|c|c|c|c|}
\hline \multirow{2}{*}{$\begin{array}{l}\text { BEL statement } \\
\#\end{array}$} & \multicolumn{6}{|c|}{ Student mean misconception number change (SD) } \\
\hline & Category & Teacher with misconception & Teacher without misconception & $t$ & $d f$ & $p$ \\
\hline \multirow[t]{2}{*}{1} & SSMT1 & -0.19 & -0.01 & 2.02 & 520 & $0.04^{\mathrm{b}}$ \\
\hline & & $(0.61)$ & $(0.65)$ & & & \\
\hline \multirow[t]{2}{*}{2} & SSMT2 & 0.08 & 0.05 & 0.48 & 532 & 0.63 \\
\hline & & $(0.53)$ & $(0.52)$ & & & \\
\hline \multirow[t]{2}{*}{3} & SSMT3 & 0.11 & 0.07 & 0.56 & 398 & 0.57 \\
\hline & & $(0.61)$ & $(0.56)$ & & & \\
\hline \multirow[t]{2}{*}{4} & SSMT4 & -0.05 & -0.01 & 0.57 & 495 & 0.57 \\
\hline & & $(0.55)$ & $(0.58)$ & & & \\
\hline \multirow[t]{2}{*}{5} & SSMT5 & 0.10 & 0.01 & 1.45 & 502 & 0.15 \\
\hline & & $(0.62)$ & $(0.60)$ & & & \\
\hline \multirow[t]{2}{*}{6} & $\mid \mathrm{E} 1$ & -0.09 & 0.02 & 1.57 & 534 & 0.12 \\
\hline & & $(0.60)$ & $(0.59)$ & & & \\
\hline \multirow[t]{2}{*}{7} & IE2 & -0.12 & -0.04 & 1.05 & 516 & 0.29 \\
\hline & & $(0.64)$ & $(0.62)$ & & & \\
\hline \multirow[t]{2}{*}{8} & IE3 & -0.11 & -0.03 & 0.85 & 534 & 0.39 \\
\hline & & $(0.66)$ & $(0.79)$ & & & \\
\hline \multirow[t]{2}{*}{9} & IE4 & 0.12 & 0.13 & 0.15 & 534 & 0.88 \\
\hline & & $(0.71)$ & $(0.65)$ & & & \\
\hline \multirow[t]{2}{*}{10} & IE5 & -0.04 & -0.04 & 0.11 & 514 & 0.91 \\
\hline & & $(0.70)$ & $(0.63)$ & & & \\
\hline \multirow[t]{2}{*}{11} & NE1 & 0.06 & 0.14 & 1.16 & 530 & 0.25 \\
\hline & & $(0.67)$ & $(0.64)$ & & & \\
\hline \multirow[t]{2}{*}{12} & NE2 & -0.05 & -0.05 & 0.15 & 534 & 0.88 \\
\hline & & $(0.46)$ & $(0.53)$ & & & \\
\hline \multirow[t]{2}{*}{13} & NE3 & 0.02 & 0.08 & 1.11 & 511 & 0.27 \\
\hline & & $(0.54)$ & $(0.59)$ & & & \\
\hline \multirow[t]{2}{*}{14} & NE4 & 0.05 & -0.01 & 0.91 & 534 & 0.36 \\
\hline & & $(0.62)$ & $(0.59)$ & & & \\
\hline \multirow[t]{2}{*}{15} & ME1 & -0.11 & -0.06 & 1.44 & 534 & 0.15 \\
\hline & & $(0.72)$ & $(0.70)$ & & & \\
\hline \multirow[t]{2}{*}{16} & ME2 & 0.13 & 0.05 & 1.52 & 534 & 0.13 \\
\hline & & $(0.63)$ & $(0.61)$ & & & \\
\hline \multirow[t]{2}{*}{17} & ME3 & 0.06 & 0.05 & 0.05 & 534 & 0.96 \\
\hline & & $(0.66)$ & $(0.58)$ & & & \\
\hline \multirow[t]{2}{*}{18} & ME4 & 0.14 & 0.05 & 1.83 & 521 & 0.07 \\
\hline & & $(0.54)$ & $(0.66)$ & & & \\
\hline 19 & $M E 5^{a}$ & - - & - - & - - & - - & - - \\
\hline \multirow[t]{2}{*}{20} & ESE1 & 0.22 & -0.01 & 3.96 & 511 & $0.0001^{c}$ \\
\hline & & $(0.59)$ & $(0.59)$ & & & \\
\hline \multirow[t]{2}{*}{21} & ESE2 & -0.09 & -0.01 & 1.42 & 521 & 0.16 \\
\hline & & $(0.59)$ & $(0.58)$ & & & \\
\hline
\end{tabular}




\begin{tabular}{|c|c|c|c|c|c|c|}
\hline \multirow[t]{2}{*}{22} & ESE3 & 0.02 & -0.01 & 0.62 & 486 & 0.54 \\
\hline & & $(0.59)$ & $(0.58)$ & & & \\
\hline \multirow[t]{2}{*}{23} & ESE4 & 0.05 & -0.02 & 1.12 & 534 & 0.26 \\
\hline & & (0.59) & $(0.59)$ & & & \\
\hline
\end{tabular}

${ }^{\mathrm{a}}$ Analysis was not conducted as no teacher possessed the statement misconception. ${ }^{\mathrm{b}}$ Difference between groups was statistically significant at $p<.05$. ${ }^{\mathrm{c}}$ Difference between groups was statistically significant at $p<.01$. BEL, Biological Evolution Literacy; ESE, evidence supporting evolution; IE, intentionality of evolution; ME; mechanisms of evolution; NE, nature of evolution; SD, standard deviation; SSMT, science, scientific methodology, and terminology.

who rejected the statement misconception, producing a mean $p=.36$ (Table 9). There were likewise ten statements $(1,4,6,7,8,9,11,13,15$, and 21) in which the mean change in the number of misconceptions held by students whose teachers possessed the statement misconception was less than that for students whose teachers lacked the statement misconception, producing a mean $p=.31$ (Table 9). No mean changes in the number of misconceptions between the two groups of students were produced by statements 10 and 12 . One statement, number 19, was not analyzed because the statement misconception was not possessed by any of the teachers.

To assess the degree to which the numbers of teachers' misconceptions were linearly related to students' post-instruction BEL Survey index scores, the Pearson product-moment correlation coefficient $(r)$ was employed. Analysis revealed the correlation between teachers' number of misconceptions and students' postinstruction BEL Survey index scores was significant $(r(534)=-.17, p<.01)$. In general, the results suggest a small inverse correlation between the two variables, indicating that as the number of teachers' misconceptions increase, students' post-instruction BEL Survey mean index scores decrease and, as the number of teachers' misconceptions decrease, students' post-instruction BEL Survey mean index scores increase. However, $r^{2}$ indicates that only $2.9 \%$ of students' BEL Survey index scores were predicted by the number of teachers' misconceptions.

\section{Discussion}

\section{Comparison of students' pre- and post-instruction BEL survey results}

Students had a statistically significant increase $(p<.05)$ in BEL Survey index scores from the pre-instruction survey $(M=70.11, S D=6.97)$ to the post-instruction survey $(M=71.72, S D=8.80)$. This would seem to indicate that students possessed fewer biological evolution misconceptions following instruction as opposed to prior to instruction - a result to be expected if students' misconceptions were supplanted by accurate concepts during the teaching process. On closer examination, however, this was not the case. The total number of students' misconceptions increased by 260 following instruction, from 4,812 pre-instruction misconceptions to 5,072 postinstruction misconceptions. The discrepancy between the positive change in student BEL Survey mean index scores and the increase in mean number of misconceptions from pre- to post-instruction can primarily be accounted for by a statistically significant $(p<.01)$ reduction in the mean number of 'undecided/never heard of it' responses from pre- to post-instruction (3.92 to 2.15), coupled with statistically significant $(p<.01)$ increases in the mean number of pre- and post-instruction 'strongly agree' responses (4.20 to 4.88) and 'strongly disagree' responses (4.05 to 4.80; see Table 5). Although a slight majority of those students who selected the pre-instruction 'undecided/never heard of it' response subsequently selected the accurate post-instruction statement concepts, thus elevating the BEL Survey mean index score, a slightly smaller number selected the statements' misconceptions, which resulted in an increase in the total number of misconceptions from pre- to post-instruction.

Although students were obviously more confident in their responses following instruction, this new-found confidence was inversely correlated to their competency in the subject matter. This finding replicates similar results identified by multiple researchers (for example, Bishop and Anderson 1990; Cunningham and Wescott 2009; Wilson 2001). This increase in confidence was predominately a female phenomenon, as the average decrease in 'undecided/never heard of it' responses from pre- to post-instruction BEL Survey was 0.74 per female student $(n=287)$ but only 0.38 per male student $(n=249)$. This outcome may be because female students were more indecisive in their initial pre-instruction survey statement responses, producing a mean $4.25(n=287, S D=4.01)$ 'undecided/never heard of it' response rate for the 23 BEL Survey statements as opposed to male students' mean $3.54(n=249, S D=3.61)$ response rate, a significant difference of $t(534)=2.14, p<.05$. Such a phenomenon was likewise documented in both Almquist and Cronin's (1988) and Cunningham and Wescott's (2009) studies.

Additional evidence indicating an increase in student confidence was found in the comparison of students' biological evolution knowledge self-rating scoring means 
pre- and post-instruction. Students rated themselves to be more knowledgeable about biological evolution post-instruction as opposed to pre-instruction. Again, however, the confidence gained did not correlate to increased competency in subject matter.

Researchers have observed that students are able to recognize the scientifically acceptable answer when a statement is phrased correctly, such as BEL Survey statement 2, for example, 'The scientific methods used to determine the age of fossils and the earth are reliable'. However, when a statement is put forth that includes a common misconception, such as BEL Survey statement 1, 'A scientific theory that explains a natural phenomenon can be classified as a "best guess" or "hunch", students tend to agree with the misconception (Almquist and Cronin 1988; Cunningham and Wescott 2009). The present study did find a similar trend in students' responses with correctly phrased statements $(n=10)$ accounting for a mean post-instruction student misconception rate of $198.30(S D=52.10)$ out of a possible 536 student responses, whereas statements that included a common misconception $(n=13)$ produced a mean student misconception rate of $237.62(S D=84.93)$. To Cunningham and Wescott (2009), such a trend suggested that, 'while our students may have heard the scientifically accurate definition of terms such as theory, fitness, and natural selection, they do not truly understand them' (p. 514). These researchers strongly concur.

\section{Student variables}

Previous studies have shown that student misconceptions about science can differ significantly based on multiple variables including geographical region, religious background, generation, gender, and age (Almquist and Cronin 1988; Losh et al. 2003; Morrison and Lederman 2003; Palmer 1999). This study found no significant difference between the mean difference in the number of students' pre- or post-instruction biological evolution misconceptions when related to students' gender, ethnicity, grade level, biological evolution knowledge self-rating, or to the students' public high schools' urban-centric locations or ADM. With these variables minimized as contributing factors to student acquisition of biological evolution misconceptions, the focus then turns to the role of the teacher.

\section{Teacher variables}

Even though the difference proved to be outside the realm of significant $(p=.08)$, it is interesting to note that students of male teachers had a $232.8 \%$ increase in the mean difference in the number of misconceptions from pre- to post-instruction over that of students of female teachers. This result could simply have occurred because female teachers in this study $(n=17)$ appeared to be more knowledgeable of biological evolution, with a mean BEL Survey index score of $94.40(S D=13.69)$ compared to $89.2(S D=14.6)$ in men $(n=18)$, and mean misconception rate of $4.29(S D=3.87)$ compared with 5.83 $(S D=3.78)$ in men. This explanation appears to be valid based on the results obtained when teachers' BEL Survey index scores were ranked regardless of gender, divided into either a HISG $(n=18, M=103.11, S D=5.72)$ or a LISG ( $n=17, M=79.64, S D=9.74)$, and then compared to the mean difference in students' pre- and postinstruction BEL Survey index scores and number of misconceptions. Students whose teachers' BEL Survey index scores fell in the HISG generated a BEL Survey mean index score increase of $2.58(n=290, S D=9.25)$ from pre- to post-instruction and a 0.20 mean increase in number of misconceptions $(S D=3.48)$ whereas those students whose teachers' BEL Survey index scores were in the LISG produced a BEL Survey mean index score increase of only $0.47(n=246, S D=8.40)$ coupled with a 0.82 mean increase $(S D=3.23)$ misconceptions. Thus, while teachers' gender may play a role in students' acquisition of biological evolution-related misconceptions, a more important factor appears to be the biological evolution knowledge possessed by the teachers themselves. Certainly additional research is warranted in this area.

Whereas significant differences $(p<.05)$ were discovered in the mean difference in number of students' preand post-instruction misconceptions between students whose teachers possessed either bachelor's or master's degrees and students whose teachers possessed doctorate degrees, one must proceed with caution. Only 43 of the 536 student participants were students of teachers possessing doctorate degrees $(n=3)$, representing only $8.0 \%$ of the student population, whereas 169 (31.5\%) were students of teachers possessing terminal master's degrees $(n=10)$, and $324(60.5 \%)$ were students of teachers possessing terminal bachelor's degrees $(n=22)$. No doubt, larger sample sizes of teachers possessing doctorates, along with their students, are required to verify the results of this study. It is interesting to note, however, students $(n=324)$ of teachers possessing terminal bachelor's degrees had a mean increase of 0.27 $(S D=3.36)$ misconceptions following instruction as compared to a mean increase of $0.45(S D=3.28)$ misconceptions for students $(n=169)$ of teachers possessing terminal master's degrees. Results of this study indicate that such a difference in students' mean number of misconceptions from pre- to post-instruction may be more closely tied to the teacher's bachelor's degree field than to terminal degree level as previous research has revealed that teachers' understanding of content is nearly directly correlated with their education (Hoy et al. 2006; Pajares 1992). Students of teachers possessing science education, non-biology science, and biology 
bachelor's degrees had mean misconception increases from pre- to post-instruction of $0.08(n=125, S D=3.04), 0.11$ $(n=122, S D=3.46)$, and $0.57(n=195, S D=3.34)$ respectively, whereas students of teachers possessing non-science bachelor's degrees had a mean pre- to post-instruction increase of $1.50(n=180, S D=3.71)$ misconceptions. Significant differences $(p<.05)$ revealed between the mean difference in numbers of pre- and post-instruction misconceptions between students of teachers possessing either science education or non-biology science bachelor's degrees and students of teachers possessing non-science bachelor's degrees indicate that students' numbers of biological evolution-related misconceptions are more likely to increase from pre- to post-instruction if they are taught by teachers lacking science-related bachelor's degrees. Approximately $54.5 \%(n=12)$ of those teachers with terminal bachelor's degrees $(n=22)$ held either a science education or non-biology science degree compared to only $30.0 \%$ $(n=3)$ of those teachers possessing terminal master's degrees $(n=10)$, and $0.0 \%$ of those teachers holding doctorate degrees $(n=3)$, while their students produced mean pre- to post-instruction misconception number increases of $0.27(S D=3.36), 0.45(S D=3.28)$, and $2.21(S D=3.39)$ respectively.

No significant differences were discovered in the mean difference between students' numbers of pre- and postinstruction misconceptions when related to their teachers' years of teaching experience, teachers' rating of emphasis placed on biological evolution in their college courses, or teachers' self-rating of biological evolution knowledge. However, statistically significant differences $(p<.01)$ in the mean difference between students' numbers of pre- and post-instruction misconceptions were related to the number of hours teachers dedicated to teaching biological evolution concepts in the Biology I course, with 6 to 10 hours of teacher instruction identified as the optimum duration. Although 6 to 10 hours of evolution instruction did not appear to reduce the number of misconceptions students brought into the classroom, this duration did seem to inhibit their development as compared to shorter or longer durations of instruction where the number of students' misconceptions increased from their initial levels by levels higher than the 0.01 mean increase afforded by the 6 to 10 hours of instruction. Interestingly, one teacher in the study indicated dedicating no hours to the teaching of evolution in the Biology I course yet produced the most favorable student results. This teacher's students $(n=17)$ had a mean decrease of $1.0(S D=2.98)$ misconceptions from pre- to post-instruction BEL Survey while presumably lacking any teacher instruction. Of course, the accuracy and quality of the evolution instruction is no doubt more important than the quantity of time spent teaching evolutionary concepts in the classroom.

\section{BEL survey statement analysis}

Especially enlightening were those results obtained when the 35 teachers' BEL Survey index scores were ranked from highest to lowest, subsequently divided into two groups - the HISG and the LISG - and the mean change in both groups' students' BEL Survey index scores and number of misconceptions from pre- to post-instruction were analyzed. Results revealed that from pre- to postinstruction, those students of teachers classified in the HISG produced a significantly higher $(p<.01)$ BEL Survey mean index score coupled with a significantly lower $(p<.05)$ mean number of misconceptions than did those students whose teachers were classified in the LISG (keeping in mind that the mean number of misconceptions increased for both groups of students from pre- to post-instruction). These results indicate that students of teachers who possess a relatively better knowledge of biological evolution have an increased opportunity to learn and retain biological evolution-related concepts. While the data do not indicate a concurrent reduction in evolution misconceptions, these students have an opportunity to minimize the number of new misconceptions acquired during the course of instruction as opposed to those students taught by teachers with a relatively poorer knowledge of biological evolution concepts. Studies repeatedly show the positive impact effective teachers can have on student achievement. For example, both Sanders and Horn (1994) and Marzano (2003) revealed a 39.0 percentage point difference in student achievement gains between students with most effective and least effective teachers (as cited in Miller 2003, p. 2).

When each of the 23 BEL Survey statements was independently analyzed to determine which teachers possessed the associated misconception and which did not, followed by analysis of the mean change in their students' numbers of misconceptions from pre-instruction to post-instruction, the data revealed conflicting results (Table 9). Analysis revealed ten BEL Survey statements in which the mean positive change in the number of misconceptions held by students whose teachers adhered to the statement misconception were greater than the mean positive change in the number of misconceptions held by students of teachers who did not possess the statement misconception. There were likewise ten survey statements in which the mean positive change in the number of misconceptions held by students whose teachers possessed the statement misconceptions were less than the mean positive change in the number of misconceptions held by students of teachers who lacked the misconception. Only one of the 10 survey statements that were revealed as possible contenders for the transmission of the statement misconception from teacher to student did so at a statistically significant level. This statement, number 20 ('There exists a large amount of 
evidence supporting the theory of evolution'), produced a $0.22(S D=0.59)$ increase in the mean number of misconceptions from pre- to post-instruction in those students whose teachers possessed the misconception as opposed to a $0.01(S D=0.59)$ decrease in students whose teachers lacked the misconception. At the $p=.0001$ level of significance, there exists a high probability that this particular misconception was passed from teacher to student. Were other misconceptions passed from teacher to student? Most likely, as several other BEL Survey statements teetered on the brink of statistical significance (Table 9) but only statement 20 crossed the line at the $p<.05$ level of significance.

Even though analysis identified only one BEL Survey statement misconception with a high probability of being transmitted from teachers to their students, the study did reveal an important relationship between teachers' levels of misconceptions and student achievement which may provide additional evidence of misconception transmission from teachers to students. Results suggest an inversely correlated relationship between the number of teachers' misconceptions and students' postinstruction BEL Survey index scores, that is, as the number of teachers' misconceptions increased, students' BEL Survey post-instruction index scores decreased and, as the number of teachers' misconceptions decreased, students' BEL Survey post-instruction index scores increased. Transmission of misconceptions from these teachers to their students cannot be ruled out as a causative agent although several variables may come into play in the decrease of students' post-instruction BEL Survey index scores following instruction by teachers with high levels of misconceptions as evidenced by the fact that Pearson's $r^{2}$ indicated that only $2.9 \%$ of students' postinstruction BEL Survey index scores were predicted by the number of teachers' misconceptions.

\section{Limitations of study}

Several possible limitations were evident in this study. For example, all teacher participants volunteered for the study and therefore are probably not a truly random sample of all Oklahoma public high school Biology I teachers. Similarly, during the duration of the study some students may have been exposed to biological evolution misconceptions in non-biology courses or in other contexts. In addition, for some variables tested, small teacher and/or student sample sizes may have produced results that were not representative of the population as a whole. In light of these limitations, a completely causative link between students' acquisition of biological evolution misconceptions and the variables defined within the study is not assigned. Nevertheless, evidence suggests that the data reported here are reliable and representative, and the results are consistent with those reported by previous researchers (for example, Almquist and Cronin 1988; Bishop and Anderson 1990; Cunningham and Wescott 2009; Wilson 2001).

\section{Conclusions}

This study revealed some problematic issues concerning the teaching of biological evolution in Oklahoma's public high school introductory biology course, as evidenced by the fact that the average student in the study completed the Biology I course with increased confidence in their biological evolution knowledge yet with a greater number of biological evolution misconceptions and, therefore, less competency in the subject. Who is culpable? Certainly one's first compulsion is to implicate the teacher. Such a verdict may be justified in many cases as research has revealed ' ... instruction in evolutionary biology at the high school level has been absent, cursory, or fraught with misinformation' (Rutledge and Mitchell 2002 p. 21) and 'about one-fourth of Oklahoma public school life-science teachers place moderate or strong emphasis on creationism' (Weld and McNew 1999, p. 52). Disturbingly, this study revealed two cases in which students who entered their Biology I courses held a higher pre-instruction BEL Survey mean index score than the BEL Survey index scores produced by their respective teachers on the identical survey. This result indicates that these students, on average, had a more accurate understanding of biological evolution prior to instruction than did the teachers whose task was to instruct them in the topic. Based on this result alone, there is little doubt that teachers may serve as sources of biological evolutionrelated misconceptions or, at the very least, propagators of existing misconceptions.

Identifying the sources of misconceptions is difficult at best. While this study focused primarily on teachers as a source of student biological evolution misconceptions, other contributing factors may certainly have played a role, including religious and parental influences, textbooks, and popular media, all of which have been known to foster student misconceptions (for example, Cavallo and McCall 2008; Linhart 1997), as well as content and teachers associated with other courses. Evidence also exists that the topic of evolution is too complex for high school students, most of whom still think at the concrete level, lacking the cognitive development necessary to comprehend biological evolution-related concepts fully and are therefore unable to construct solid accurate understandings of the topic (Lawson and Thompson 1988; Settlage 1994). No doubt, multiple factors contribute in varying degrees to the acquisition and retention of student misconceptions of biological evolution. It is imperative, then, that we as educators identify sources of student biological evolution-related misconceptions, identify or develop strategies to reduce or eliminate 
such misconceptions, and then implement these strategies at the appropriate junctures in students' cognitive development. If teachers are unaware of the misconceptions prevalent with students and do not take them into consideration when implementing instructional strategies, they may hold overly optimistic expectations of the effectiveness of their teaching (Lightman and Sadler 1993).

The Oklahoma Academy of Science strongly supports thorough teaching of evolution in biology classes, deeming evolution one of the most important principles of science while noting that 'a high school graduate who does not understand evolution is not prepared for college or for life in a technologically advanced world in which the role of biology and biotechnology will continue to grow' (Oklahoma Academy of Science 2007, p. 1) These graduates deserve a high school biology teacher who functions not as a source of students' misconceptions but rather as a resource for their identification and elimination. Yet, students' knowledge structures have been found to approximate those of their teachers (Rutledge and Mitchell 2002), and currently substantial numbers of biology students become biology teachers while still retaining major misconceptions (Nehm et al. 2008). We must work diligently to disrupt this cycle.

\section{Abbreviations}

ADM: average daily membership; ANOVA: analysis of variance; BEL: Biological Evolution Literacy; ESE: evidence supporting evolution; HISG: high index score group; IE: intentionality of evolution; LISG: Iow index score group; ME: mechanisms of evolution; NE: nature of evolution; PASS: Priority Academic Student Skills; SSMT: science, scientific methodology, and terminology.

\section{Competing interests}

The authors declare that they have no competing interests.

\section{Authors' contributions}

TBY devised the research problem, drafted the BEL Survey, carried out and interpreted the research results. EAM contributed to the conception and design of the research project and critically revised the manuscript for intellectual content. All authors read and approved the final manuscript.

\section{Author details}

${ }^{1}$ Oklahoma Baptist University, James E. Hurley College of Science and Mathematics, 500 West University, OBU Box 61722, Shawnee, OK 74804, USA. ${ }^{2}$ Department of Instructional Leadership and Academic Curriculum, University of Oklahoma, 114 Ellsworth Collings Hall, Norman, OK 73019-0260, USA.

Received: 19 June 2013 Accepted: 11 February 2014

Published online: 28 March 2014

\section{References}

Affanato, RE. (1986). A survey of biology teachers' opinions about the teaching of evolution and/or the creation model in the United States in public and private schools. lowa City: Dissertation: University of lowa.

Almquist, JJ, \& Cronin, JE. (1988). Fact, fancy, and myth on human evolution. Current Anthropology, 29, 520-522.

Alters, BJ, \& Alters, SM. (2001). Defending evolution: a guide to the creation evolution controversy. Sudbury, MA: Jones and Bartlett.

Alters, BJ, \& Nelson, CE. (2002). Perspective: teaching evolution in higher education. Evolution, 56, 1891-1901.
American Association for the Advancement of Science. (1993). Benchmarks for science literacy. New York: Oxford University Press.

Barrass, R. (1984). Some misconceptions and misunderstandings perpetuated by teachers and textbooks of biology. Journal of Biological Education, 18(3), 201-206

Bishop, BA, \& Anderson, CW. (1986). Evolution by natural selection: a teaching module. Occasional paper 91. Michigan State University: East Lansing: Institute for Research on Teaching. ERIC No. ED272383.

Bishop, BA, \& Anderson, CW. (1990). Student conceptions of natural selection and its role in evolution. Journal of Research in Science Teaching, 27, 415-427.

Brumby, M. (1984). Misconceptions about the concept of natural selection by medical biology students. Science Education, 68, 493-503.

Cavallo, AML, \& McCall, D. (2008). Seeing may not mean believing: examining students' understandings \& beliefs in evolution. American Biology Teacher, 70, 522-530.

Chinsamy, A, \& Plagányi, È. (2007). Accepting evolution. Evolution, 62, 248-254

Clough, EE, \& Wood-Robinson, C. (1985). How secondary students interpret instances of biological adaptation. Journal of Biological Education, 19, 125-130

Crawford, BA, Zembal-Saul, C, Munford, D, \& Friedrichsen, P. (2005). Confronting prospective teachers' ideas of evolution and scientific inquiry using technology and inquiry-based tasks. Journal of Research in Science Teaching, 42(6), 613-637.

Cunningham, DL, \& Wescott, DJ. (2009). Still more "fancy" and "myth" than "fact" in students' conceptions of evolution. Evolution Education and Outreach, 2, 505-517.

Dagher, ZR, \& BouJaoude, S. (2005). Students' perceptions of the nature of evolutionary theory. Science Education, 89, 378-391.

Demastes, SS, Good, R, \& Peebles, P. (1995). Students' conceptual ecologies and the process of conceptual change in evolution. Science Education, 79, 637-666.

Driver, R, Squires, A, Rushworth, P, \& Wood-Robinson, V. (1994). Making sense of secondary science. New York, NY: Routledge.

Evans, EM. (2001). Cognitive and contextual factors in the emergence of diverse belief systems: creation versus evolution. Cognition Psychology, 42, 217-266.

Ferrari, M, \& Chi, MTH. (1998). The nature of naïve explanations of natural selection. International Journal of Science Education, 20, 1231-1256.

Fisher, KM. (2004). The importance of prior knowledge in college science instruction. In DW Dunal, EL Wright, \& JB Day (Eds.), Reform in undergraduate science teaching for the $21^{\text {st }}$ century (pp. 69-83). Greenwich, CT: Information Age Publishing.

Greene, ED, Jr. (1990). The logic of university students' misunderstanding of natural selection. Journal of Research in Science Teaching, 27, 875-885.

Gregory, TR. (2009). Understanding natural selection: essential concepts and common misconceptions. Evolution: Education and Outreach, 2, 156-175.

Haidar, AH. (1997). Prospective chemistry teachers' conceptions of the conservation of matter and related concepts. Journal of Research in Science Teaching, 34, 181-197.

Hokayem, H, \& BouJaoude, S. (2008). College students' perceptions of the theory of evolution. Journal of Research in Science Teaching, 45, 395-419.

Hoy, A, Davis, H, \& Pape, SJ. (2006). Teacher knowledge and beliefs. In PA Alexander \& PH Winne (Eds.), Handbook of educational psychology (2nd ed. pp. 715-737). Mahwah, NJ: Lawrence Erlbaum.

Institute of Education Sciences National Center for Educational Statistics (2010a). Digest of education statistics appendix b: Definitions. http://nces.ed.gov/ccd/ rural_locales.asp. Accessed 22 October 2010.

Institute of Education Sciences National Center for Educational Statistics (2010b). Common core of data. http://nces.ed.gov/ccd/rural_locales.asp. Accessed 22 October 2010.

Jarvis, T, Pell, A, \& McKeon, F. (2003). Changes in primary teachers' science knowledge and understanding during a two year in-service programme. Research in Science and Technology Education, 21, 17-42.

Jensen, MS, \& Finley, FN. (1996). Changes in students' understanding of evolution resulting from different curricular and instructional strategies. Journal of Research in Science Teaching, 33, 878-900.

Jiménez-Aleixandre, MP, \& Fernández-Pérez, J. (1987). Selection or adjustment? Explanations of university biology students for natural selection problems. In JD Novak (Ed.), Proceedings of the second international seminar on misconceptions and educational strategies in science and mathematics (Vol. 2, pp. 224-232). Ithaca NY: Department of Education, Cornell University. 
Kikas, E. (2004). Teachers' conceptions and misconceptions concerning three natural phenomena. Journal of Research in Science Teaching, 41(5), 432-448

Lawrenz, F. (1986). Misconceptions of physical science concepts among elementary school teachers. School Science and Mathematics, 86, 654-660.

Lawson, AE, \& Thompson, LD. (1988). Formal reasoning ability and misconceptions concerning genetics and natural selection. Journal of Research in Science Teaching, 25, 733-746.

Lightman, A, \& Sadler, P. (1993). Teacher predictions versus actual student gains. Physics Teacher, 31, 162-167.

Linhart, YB. (1997). The teaching of evolution - we need to do better. BioScience, 47, 385-391.

Losh, SC, Travani, CM, Njoroge, R, Wilke, R, \& McAuley, M. (2003). What does education really do? Educational dimensions and pseudoscience support in American general public, 1979-2001. Skeptic Inquirer, 27, 30-36.

Marzano, RJ. (2003). What works in schools: Translating research into action. Alexandria, VA: Association for Supervision and Curriculum Development.

Mazur, A. (2004). Believers and disbelievers in evolution. Politics and the Life Sciences, 23(2), 55-61.

McComas, WF. (2006). Investigating evolutionary biology in the laboratory. Dubuque, Wl: Kendall/Hunt.

Meir, E, Perry, J, Herron, JC, \& Kingsolver, J. (2007). College students' misconceptions about evolutionary trees. American Biology Teacher 69(7), 71-76.

Miller, K. (2003). School, teacher, and leadership impacts on student achievement. (Midcontinent Research for Education and Learning Policy Brief). Aurora, CO: MCREL.

Modell, H, Michael, J, \& Wenderoth, MP. (2005). Helping the learner to learn: the role of uncovering misconceptions. American Biology Teacher, 67, 20-26.

Mohapatra, JK, \& Bhattacharyya, S. (1989). Pupils, teachers, induced incorrect generalization and the concept of force. International Journal of Science Education, 11, 429-436.

Moore, R. (2009). Teaching evolution: do state science standards matter? Reports of the National Center for Science Education, 21, 19-21.

Morrison, JA, \& Lederman, NG. (2003). Science teachers' diagnosis and understanding of students' perceptions. Science Education, 87, 849-867.

National Academy of Sciences. (1998). Teaching about evolution and the nature of science. Washington DC: National Academy Press.

National Research Council. (1996). National science education standards. Washington, DC: National Academy Press.

Nehm, RH, \& Schonfeld, IS. (2007). Does increasing biology teacher knowledge of evolution and the nature of science lead to greater preference for the teaching of evolution in schools? Journal of Science Teacher Education, 18, 699-723.

Nehm, RH, Poole, TM, Lyford, ME, Hoskins, SG, Carruth, L, Ewers, BE, \& Colberg, PJS. (2008). Does the segregation of evolution in biology textbooks and introductory courses reinforce students' faulty mental models of biology and evolution? Evolution Education Outreach, 2, 527-532.

Novak, JD. (2002). Meaningful learning: the essential factor for conceptual change in limited or inappropriate propositional hierarchies leading to empowerment of learners. Science Education, 86, 548-571.

Oklahoma Academy of Science (2007). Statement on science, religion, and teaching evolution. http://www.oklascience.org/OASstmnt.pdf. Accessed 23 September 2009.

Oklahoma State Board of Education (2011). Oklahoma teacher licensure and certification procedures. http://ok.gov/sde/sites/ok.gov.sde/files/documents/ files/CertificationProcedures.pdf. Accessed 9 March 2014.

Oklahoma State Department of Education (2008-2009). Oklahoma end-ofinstruction Biology I alignment blueprint. https://www.alcaweb.org/arch.php/ resource/view/66104 Accessed 20 July 2009.

Oklahoma State Department of Education (2009a). Priority academic student skills. http://ok.gov/sde/sites/ok.gov.sde/files/C3\%20PASS\%20sci.pdf. Accessed 12 June 2009.

Oklahoma State Department of Education. (2009b). 2009-2010 Oklahoma directory of education. Oklahoma City: Oklahoma State Department of Education.

Oklahoma State Department of Education (2009c). ACE graduation checklist: Oklahoma requirements for high school graduation, student testing, and Oklahoma promise. http://ok.gov/sde/sites/ok.gov.sde/files/ACE-Checklist.pdf. Accessed 9 March 2014.

Osif, BA. (1997). Evolution and religious beliefs: a survey of Pennsylvania high school teachers. American Biology Teacher, 59, 522-556.
Pajares, MF. (1992). Teachers' beliefs and educational research: cleaning up a messy construct. Review of Educational Research, 62, 307-332.

Palmer, DH. (1999). Exploring the link between students' scientific and nonscientific conceptions. Science Education, 83, 639-653.

Palmquist, BC, \& Finley, FN. (1997). Preservice teachers' views of the nature of science during a postbaccalaureate science teaching program. Journal of Research in Science Teaching, 34, 595-615.

Rutledge, ML, \& Mitchell, MA. (2002). High school biology teachers' knowledge structure, acceptance \& teaching of evolution. American Biology Teacher, 64, 21-28.

Sadler, TD. (2005). Evolutionary theory as a guide to socioscientific decision making. Journal of Biological Education, 39, 68-72.

Sanders, M. (1993). Erroneous ideas about respiration: the teacher factor. Journal of Research in Science Teaching, 30, 919-934

Sanders, WL, Horn, SP. (1994). The Tennessee value-added assessment system (TVAAS): Mixed-model methodology in educational assessment. Journal of Personnel Evaluation in Education, 8, 299-311.

Settlage, J. (1994). Conceptions of natural selection: a snapshot of the sense-making process. Journal of Research in Science Teaching, 31, 449-457.

Wanderssee, JH, Mintzes, JJ, \& Novak, JD. (1994). Research in alternative conceptions in science: part II learning. In DL Gabel (Ed.), Handbook of research on science teaching and learning (pp. 177-210). New York: Macmillan.

Weld, J, \& McNew, JC. (1999). Attitudes toward evolution. In RW Bybee (Ed.), Evolution in perspective: the science teacher's compendium (pp. 49-55). Arlington, VA: NSTA Press.

Wescott, DJ, \& Cunningham, DL. (2005). Recognizing student misconception about science and evolution. Mountain Rise, 2, 1-8.

Wilson, JA. (2001). Pseudoscientific beliefs among college students. Reports of the National Center for Science Education, 21(1-20), 9-13.

Wood-Robinson, C. (1994). Young people's ideas about inheritance and evolution. Studies in Science Education, 24, 29-47.

Yates, T, \& Marek, EA. (2011). A regional study of the types and prevalence of biological evolution-related misconceptions held by public secondary school biology teachers (Paper presented at the International Conference of the National Association for Researchers in Science Teaching). Orlando, FL.

Yates, TB, \& Marek, EA. (2013). Is Oklahoma really OK? A regional study of the prevalence of biological evolution-related misconceptions held by introductory biology teachers. Evolution Education and Outreach, 6, 1-20.

Yip, DY. (1998). Teachers' misconceptions of the circulatory system. Journal of Biological Education, 32, 207-215.

\section{doi:10.1186/s12052-014-0007-2}

Cite this article as: Yates and Marek: Teachers teaching misconceptions: a study of factors contributing to high school biology students' acquisition of biological evolution-related misconceptions. Evolution: Education and Outreach 2014 7:7.

\section{Submit your manuscript to a SpringerOpen ${ }^{\circ}$ journal and benefit from:}

- Convenient online submission

- Rigorous peer review

- Immediate publication on acceptance

- Open access: articles freely available online

- High visibility within the field

- Retaining the copyright to your article

Submit your next manuscript at springeropen.com 